\title{
Multi-point Design and Optimization of a Turboshaft Engine for a Tiltwing Turboelectric VTOL Air Taxi
}

\author{
Jeffryes W. Chapman* \\ NASA Glenn Research Center, Cleveland, $\mathrm{OH}, 44135$, USA
}

This paper describes the design of a turboshaft engine for a tiltwing air taxi application. In this case, the tiltwing air taxi is intended to fly a $400 \mathrm{~nm}$ mission with up to fifteen passengers. Engine requirements for the concept engine are taken from aircraft system studies where thrust is produced by four propellers driven by electric motors and powered by a single gas turbine engine. The purpose of this paper is to perform a cycle design optimization that minimizes fuel consumption and weight while respecting current technology limitations to meet mission requirements. To achieve results, the engine overall pressure ratio and maximum temperature at the exit of the combustor are set as the design parameters. Several sensitivity studies are also performed to visualize optimization trends. Results of the optimization study show solutions are heavily dependent on engine cooling flow requirements and exact mission requirements. This engine is intended for use in large system optimization research.

\section{Alt

\section{Nomenclature}

\author{
Altitude \\ Throat area, in ${ }^{2}$ \\ Contingency rated power \\ Change in temperature wrt. standard day \\ Efficiency \\ Intermediate rated power \\ International standard Atmosphere \\ Fuel to air ratio \\ Maximum continuous power \\ Mach number \\ Maximum rated power \\ Shaft speed, rpm \\ Out of ground effects \\ Overall pressure ratio \\ Power, hp \\ Pressure ratio \\ Power specific fuel consumption, lbm/h/shp \\ Sea level static conditions \\ Blade temperature, ${ }^{\circ} \mathrm{R}$ \\ Temperature at station 4 (turbine inlet temperature), ${ }^{\circ} \mathrm{R}$ \\ Vertical takeoff and landing \\ Mass flow, lbm/s \\ Fuel mass flow, lbm/s
}

\section{Subscripts}

* Research Engineer, 21000 Brookpark Rd., Cleveland OH, AIAA Member.

Adiabatic

Compressor 


$\begin{array}{ll}\text { core } & \text { Engine core } \\ \text { Des } & \text { Design } \\ \text { eng } & \text { Engine } \\ \text { gen } & \text { Generator } \\ \text { max } & \text { Maximum } \\ \text { noz } & \text { Nozzle } \\ \text { OD1 } & \text { Off design point 1 } \\ \text { OD2 } & \text { Off design point 2 } \\ \text { poly } & \text { Polytropic } \\ \text { pt } & \text { Power turbine } \\ \text { Set } & \text { Set point } \\ \text { turb } & \text { Turbine }\end{array}$

\section{Introduction}

$\mathrm{T}$ ravel within urban environments is becoming increasingly time consuming and expensive as human populations continue to grow and migrate from urban centers. This has led to an increase in interest in alternate modes of travel, including small vertical take-off and landing (VTOL) aircraft designed for the urban environment. ${ }^{1,2}$ To meet the needs of this design space, it has been found that fully electric or hybrid-electric vehicles potentially offer increased performance with decreased cost. ${ }^{3}$ NASA has invested in developing a suite of concept vehicles meant to represent the technology required for such missions. These include the quad-copter, multi-rotor, coaxial helicopter, and tiltwing. This paper considers a tiltwing, turbo-electric vehicle concept presented by NASA ${ }^{4}$, and develops a potential turboshaft engine for the vehicle's power plant. The turboshaft is then optimized for the air-taxi mission described in Ref (4) with various potential limiting factors and design variables. This project represents a work in progress, and this engine model will be used within a large multi-disciplinary optimization research project ${ }^{5}$ that takes into account thermal, structural, aerodynamic, trajectory, acoustic, and propulsion disciplines.

The tiltwing concept is a 15 passenger turbo electric aircraft. This concept contains a single gas turbine engine that is devoted to powering four electric motor driven propellers (two per rotating wing). Vehicle mission dictates operation in two distinct states: hover and cruise. During hover, the propellers are angled upwards allowing thrust to be directed toward the ground. Once the vehicle has reached altitude (Alt) at $5000 \mathrm{ft}$, the wings rotate to a lateral position for cruise flight. This vehicle was designed for a "commuter bus like" mission where it would be expected to fly a route with multiple stops, refueling only once the entire mission is completed. This mission consists of 8 legs. In each leg, the vehicle performs a takeoff, hover, and cruise for $50 \mathrm{~nm}$, hover, and landing.

A turboshaft engine with a single compressor spool and a downstream power turbine driving a generator is being designed for this mission. Maximum required output power for this engine is specified for the hover condition. This application is similar to that used by helicopters, such as the General Electric T64 used to power the Sikorsky or the Lycoming LTC4 used to power the Chinook. ${ }^{6}$ Component efficiencies and constants for this conceptual engine are set with the assumption of current technology for small turboshafts. Component sizing is based around three distinct operating points: cruise, hover, and full power at sea level static conditions, with requirements and specifications set at the appropriate points. This type of design is considered a multi-point design process because the design is specified across more than one point of operation (more fully described in Section II).

To complete the various designs of this turboshaft, several parameters are optimized utilizing potential design values. During the design, engine parameters that relate to technology level remain constant, but values such as engine overall pressure ratio (OPR) and maximum turbine inlet temperature (T4) are used as handles for the optimization. During operation the engine's most important parameters are power specific fuel consumption (PSFC) and engine weight. For this paper, weight is estimated using a simple air mass flow to weight correlation based on a sample group of similarly sized turboshaft engines. PSFC is calculated directly from engine parameters.

This engine model is implemented using PyCycle, a cycle analysis tool built within the OpenMDAO framework. PyCycle consists of sets of turbomachinery components (compressors, turbines, combustors, nozzles, etc.) containing 0 -D thermodynamic relationships that can be combined together to create a full propulsion system. ${ }^{7,8}$ OpenMDAO is an open source package built to perform multidisciplinary design analysis and optimization (MDAO) within the python language. ${ }^{9}$ OpenMDAO provides sets of solver and optimizer tools, as well as a python development framework, that is leveraged to perform the multi-point optimization on the turboshaft model.

Subsequent sections of this paper detail the engine design and optimization study. Specifically, a detailed description of the tiltwing vehicle and the engine requirements is given in Section II. Engine model architecture and 
assumptions are detailed in Section III. A discussion of the optimization appears in Section IV. Finally, the conclusions are given in Section V.

\section{System Definition and Requirements}

The tiltwing turboelectric concept vehicle (Figure 1) developed in Ref (4) is used as the baseline requirements for an urban air-taxi mission. The vehicle's power plant is a single turboshaft powering 4 separate electric motors driving 4 propellers. A small battery is planned within the system to stabilize the DC voltage bus and provide for up to 2 minutes of emergency hover power. A diagram of the full propulsion system architecture is shown in Figure 2. Designed to carry fifteen passengers (3000 lbm payload), the two wings along the center of the fuselage rotate the propellers vertically to lift the vehicle up for takeoff and hover, or horizontally for cruise.

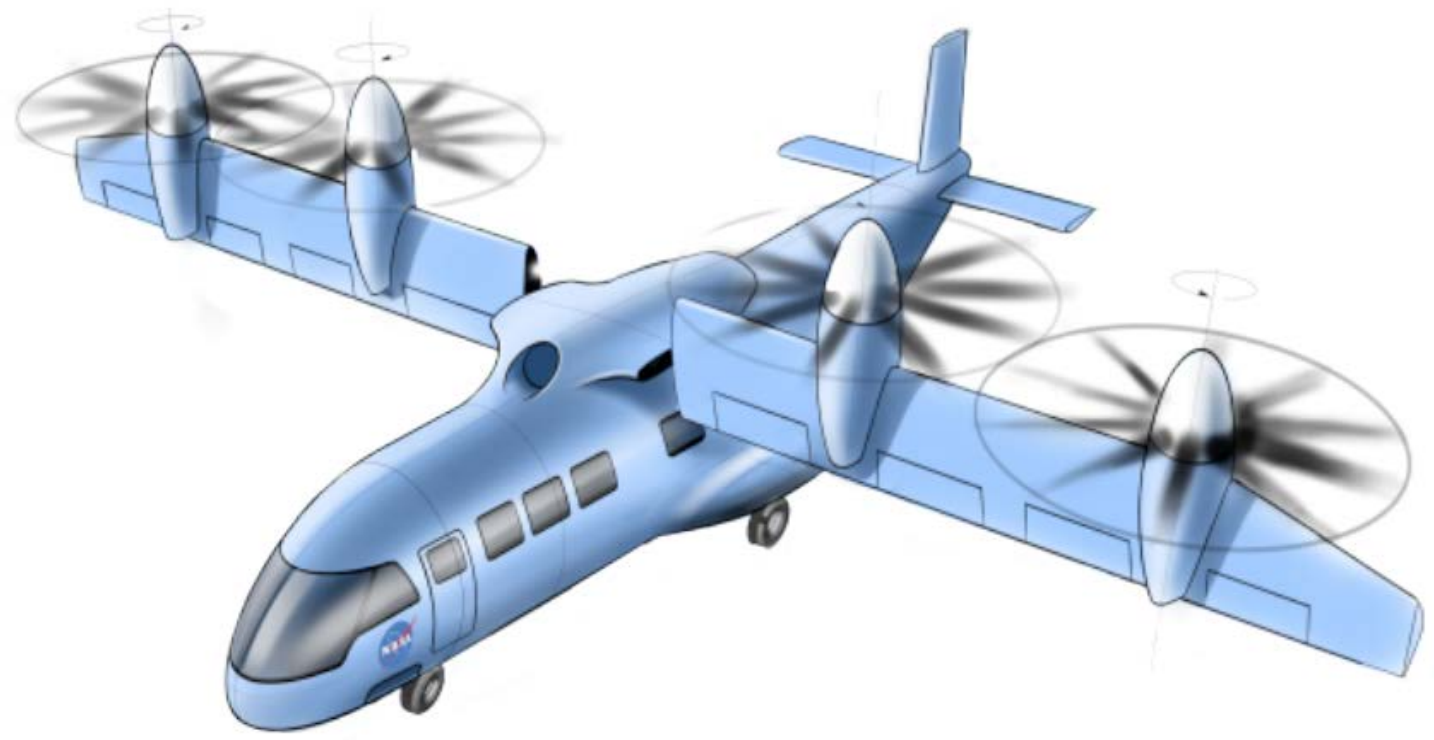

Figure 1. Tiltwing vehicle utilizing turboelectric propulsion. ${ }^{4}$

The estimated design gross weight of the vehicle is $14039 \mathrm{lbm}$ with takeoff empty weight equal to $8938 \mathrm{lbm}$ and take off fuel weight equal to $1928 \mathrm{lbm}$. The four propellers are driven by 4x730 hp electric motors with a relatively high disk loading of $30 \mathrm{lb} / \mathrm{ft}^{2}$. This leads to a hover to lift efficiency similar to that of other tiltwing vehicles, but lower than that of a typical helicopter. It is estimated that the vehicle will also have a lift-to-drag of 7.22, which is higher than helicopters, but lower than many aircraft designed for conventional take off. This combination of disk loading and lift-to-drag show that this vehicle was designed for a vertical takeoff mission with an expected speed and range greater than the typical helicopter mission. 


\section{Turboelectric}
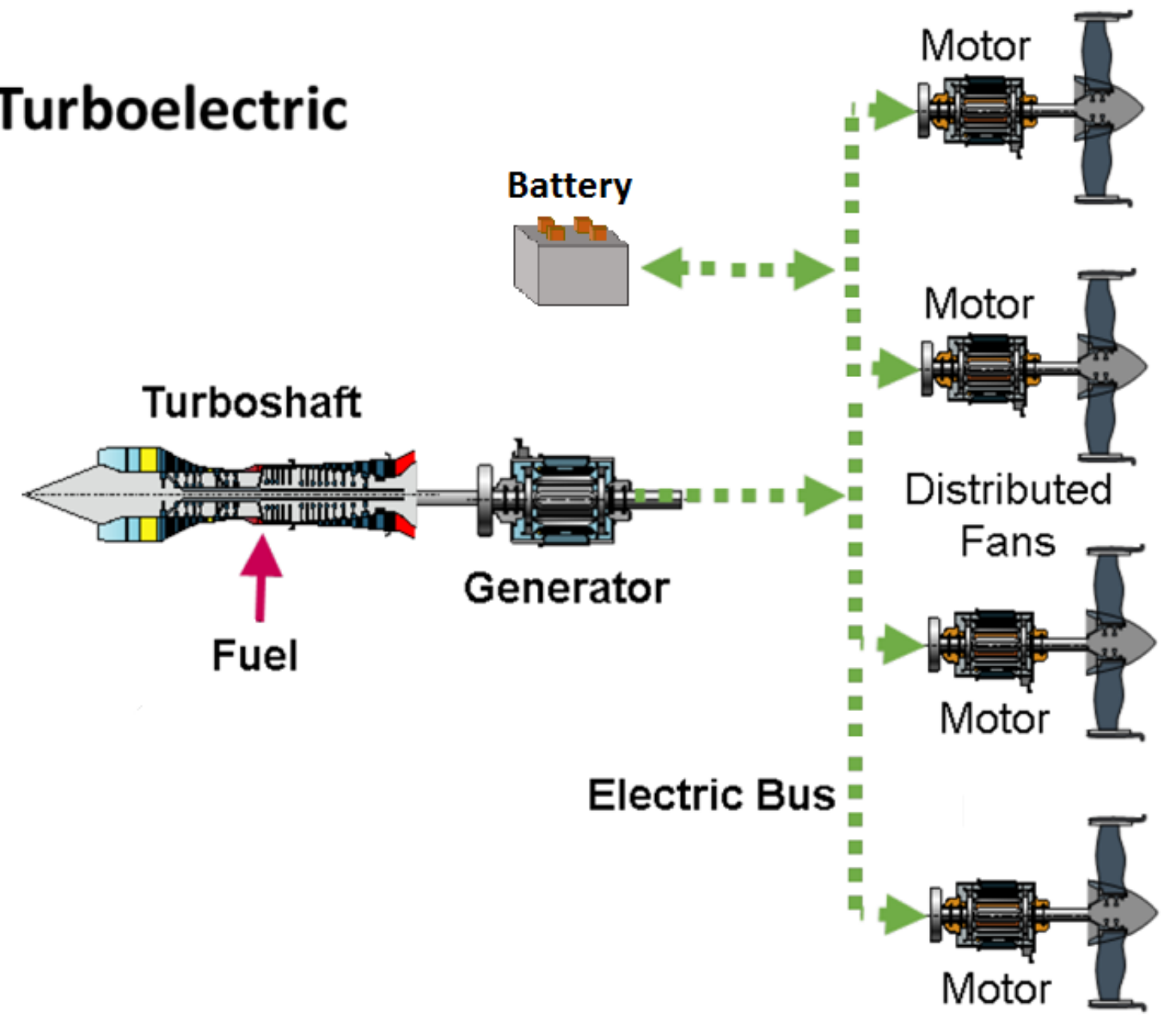

Figure 2. Turboelectric propulsion system for a 15 passenger tiltwing vehicle.

Mission requirements for this engine include the following: 2 min hover out-of-ground-effect (OGE) at takeoff; cruising $50 \mathrm{~nm}$ at a velocity of 200 knots; followed by a $2 \mathrm{~min}$ hover OGE at landing. This series will be repeated 8 times for a total mission range of $400 \mathrm{~nm}$. Flight segment are flown at an Alt of $5000 \mathrm{ft}$ and, worst case, hot day conditions (international standard atmosphere $+36^{\circ} \mathrm{R}$ ). In addition, the vehicle must maintain a $10 \%$ fuel reserve. Total motor output power is $2920 \mathrm{hp}$ and $1030 \mathrm{hp}$ for hover and cruise respectively. Cruise airspeed is, at a best endurance level, assumed to be 200 knots. Each propeller has two propeller gear states: hover at $100 \%$ rpm and cruise at $50 \% \mathrm{rpm}$. The turboshaft motor drives the generator at a constant speed. Turboshaft engine power requirements as a function of vehicle speed are shown in Figure 3, where power levels are described in Table 1 based on engine ratings defined in Ref (10). Motor and generator power required refers to electric motor and turboshaft engine requirements for the mission respectively, and do not account for auxiliary power needs and losses. At hover, the trace demonstrates a maximum power requirement at low airspeeds. At higher airspeeds, the power requirement is greatly reduced with cruise velocity of 200 knots. At this phase in the design, the electrical components have been greatly simplified and assumed to have a conservative total system efficiency of $80.6 \%$. Specific component efficiencies are detailed in Table 2 and are consistent with current technology. ${ }^{11,12}$ Note, the spike in required power at 30 knots (in Figure 3) denotes the speed at which the vehicle transitions from a hover to a cruise configuration (propellers transition from vertical to horizontal thrust) and occurs due to a loss in lift efficiency associated with wing transition. 
Table 1. Electric motor and generator/turboshaft power requirements and power ratings.

\begin{tabular}{|l|c|c|c|c|c|c|}
\hline Rating & Power Rating & Power/MCP & $\begin{array}{c}\text { Hover, 4x } \\
\text { Electric } \\
\text { Motor, hp }\end{array}$ & $\begin{array}{c}\text { Cruise, 4x } \\
\text { Electric } \\
\text { Motor, hp }\end{array}$ & $\begin{array}{c}\text { Hover, } \\
\text { Turboshaft, } \\
\text { hp }\end{array}$ & $\begin{array}{c}\text { Cruise, } \\
\text { Turboshaft, } \\
\mathbf{h p}\end{array}$ \\
\hline- & Requirement & - & $2920^{*}$ & 1030 & $3623^{* *}$ & $1280^{* *}$ \\
\hline MCP & Max continuous & 1.000 & 2464 & 1500 & 3122 & 3052 \\
\hline IRP & Intermediate rated & 1.185 & 2920 & 1778 & 3700 & 3616 \\
\hline MRP & Maximum rated & 1.269 & 3126 & 1903 & 3962 & 3872 \\
\hline CRP & Contingency rated & 1.330 & 3277 & 1995 & 4152 & 4058 \\
\hline
\end{tabular}

* 4 electric motors at $730 \mathrm{hp}$ each, ${ }^{* *}$ electric motor power/ total electrical power transport efficiency

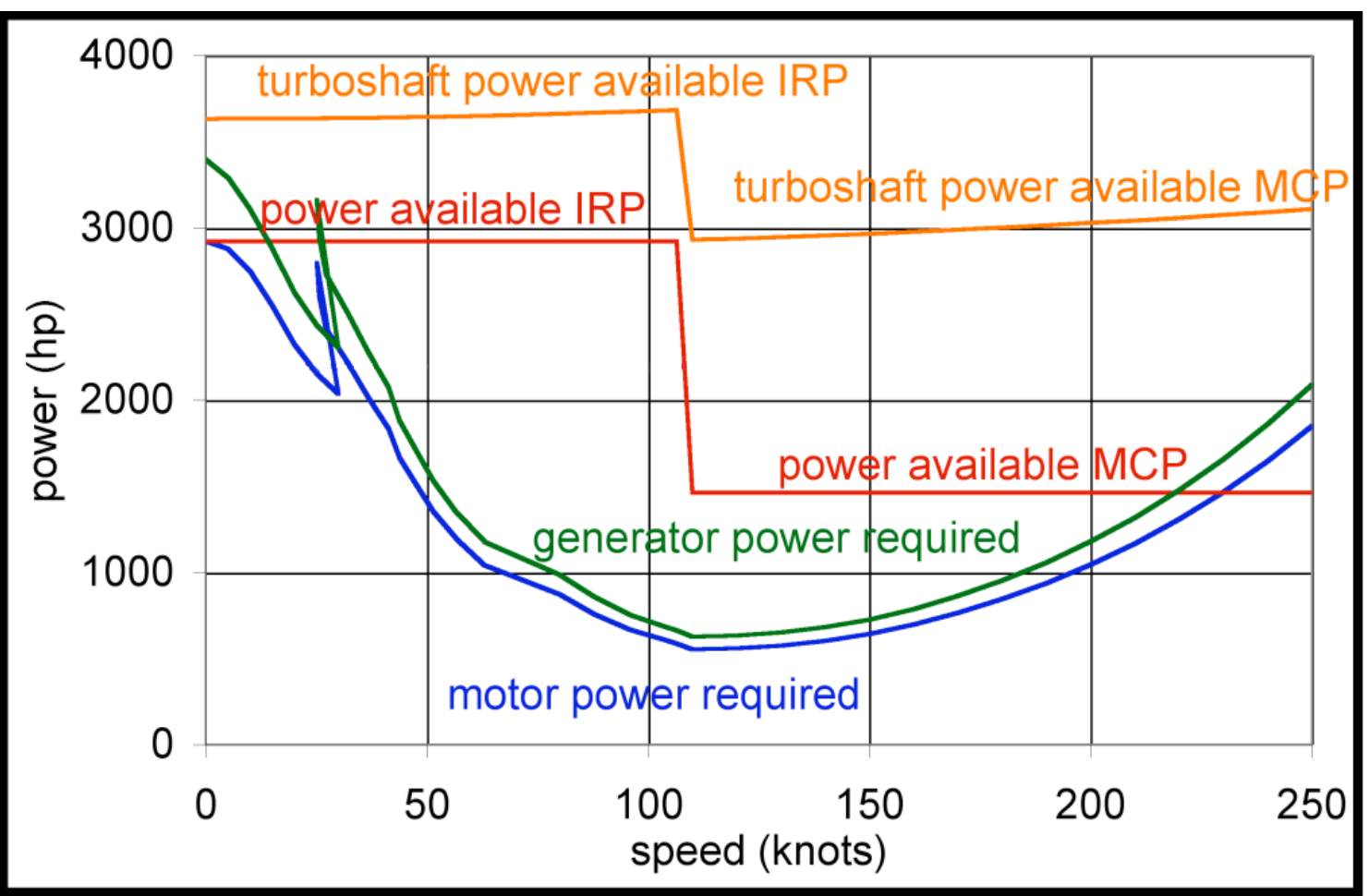

Figure 3. Tiltwing power requirements vs. speed. ${ }^{4}$

Table 2. Electric component efficiencies.

\begin{tabular}{|c|c|c|c|c|c|c|}
\hline $\begin{array}{c}\text { Electrical } \\
\text { Component }\end{array}$ & Generator & Rectifier & $\begin{array}{c}\text { Electrical } \\
\text { Bus }\end{array}$ & Inverter & Motor & $\begin{array}{c}\text { Total } \\
\text { Efficiency }\end{array}$ \\
\hline $\begin{array}{c}\text { Electrical } \\
\text { efficiency }\end{array}$ & $95 \%$ & $95 \%$ & $99 \%$ & $95 \%$ & $95 \%$ & $80.6 \%$ \\
\hline
\end{tabular}

\section{Turboshaft Description}

The turboshaft engine for a tiltwing turboelectric vehicle concept is designed around three major points: hover (max power point, used for sizing), cruise (for efficiency), and max power at sea level static (SLS) (for cross engine relationship comparisons). For this application, a single compressor spool, single power turbine spool turboshaft is chosen due to the simplicity of the architecture and the preliminary nature of the work. The single compressor spool is chosen by examining other engines in the power class and considering the added cost and complexity associated with an additional compressor spool. As a caveat, the majority of these engines are for helicopter applications and in 
these applications the power range requirement is fairly low (They run from perhaps $100 \%$ to $80 \%$ ).In this application, the power will be run from max power to roughly a third of that. It is possible that this power range requirement would cause the optimal solution to be a dual spool engine, so the more complicated architecture should be considered as more detailed analyses are completed. A component level diagram of the considered engine architecture is shown in Figure 4 and design point definitions are shown in Table 3. It should be noted that the rated powers discussed in Table 1 will be used for reference only and it will be assumed that rated powers greater than the requirement can be met by running the engine beyond the design points.

The engine model itself is created using PyCycle, ${ }^{7,8}$ a thermodynamic modeling library build on top of OpenMDAO. This package is designed to create element level models that contain 0-D flow elements based on energy balance assumptions. Elements within the package include compressors, burners, and turbines. Performance of turbomachinery is specified with the use of maps that correlate corrected speed, corrected mass flow, and pressure ratio to efficiency. Thermodynamic properties of the flow at various points are determined based on the chemical equilibrium of a fuel air mixture calculated using equations of Gibbs free energy. ${ }^{13}$ Mass flow through components is calculated within certain elements and a Newton solver is then used to converge the total system.

Engine parameters are determined based on technology level, engineering assumptions, engine class, or solved for within the simulation. Pressure drop across the combustor, the nozzle's thrust loss coefficient (in this case a coefficient of velocity), the design shaft speeds, nozzle pressure ratio, and max turbine blade temperatures are considered constant engine parameters and chosen based on a technology level assumption. Turbine and power turbine polytropic efficiencies are an assumed value and the compressor polytropic efficiency is derived from a generic small engine curve, shown in Figure 5. ${ }^{14}$ This small engine curve illustrates the correlation between corrected mass flow at the exit of compressor (core size) and polytropic efficiency. Lower efficiencies are observed at low corrected flow and higher efficiencies at higher mass flow rates. It should be noted that the small engine curve offers better efficiencies at lower corrected flow rates than those for larger engines, but lower efficiencies at higher mass flow rates. This is because of the difficulties associated with making a high efficiency compressor small, such as blade tip clearance or other manufacturing challenges. ${ }^{6}$ With the polytropic efficiencies set, component adiabatic efficiencies are solved for implicitly within the model. Flight conditions and power requirements are set based on the operational point at which the engine was run.

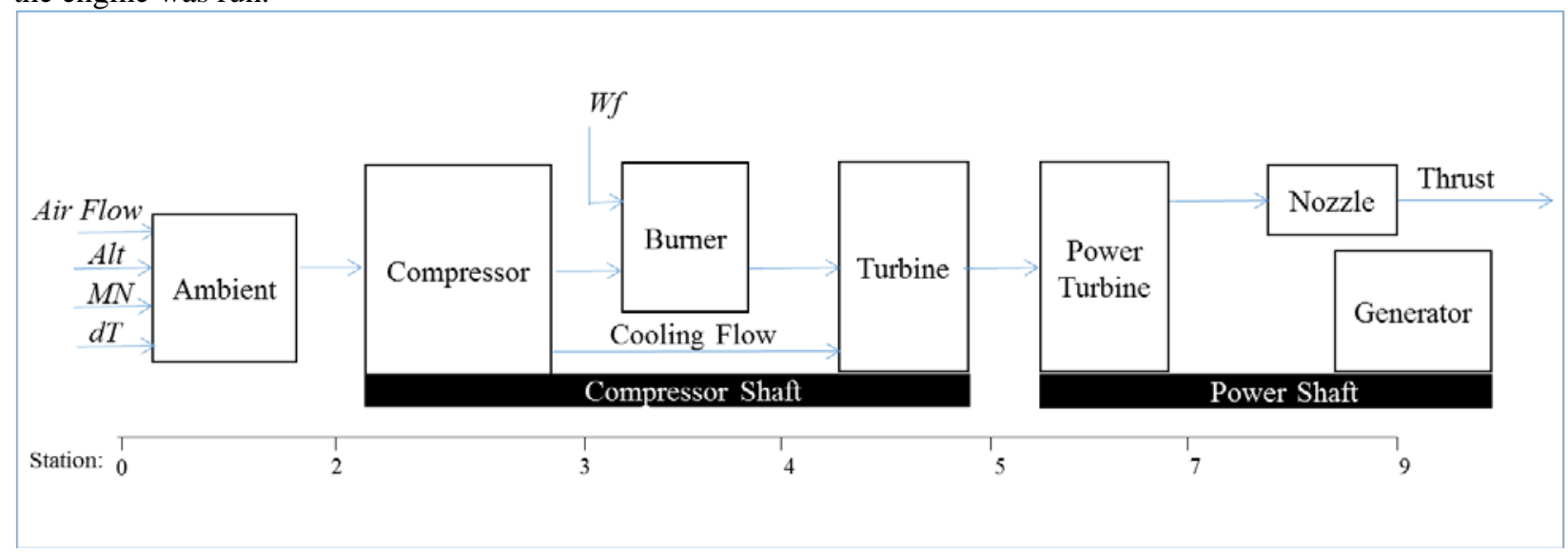

Figure 4. Turboshaft engine architecture.

Design parameters for this engine are considered to be OPR and the turbine inlet temperature (T4) limit. While these values are adjusted during the design, they are also required to observe maximum value constraints. In the case of OPR, a maximum possible value of 19 is set by assuming that any increase in pressure ratio over 19 requires adding a low pressure spool. A maximum possible T4 limit is assumed to be $3500^{\circ} \mathrm{R}$ (generally a very hot limit) due to inadequate combustor mechanism cooling. Typically, turbine operation is limited by cooling of the turbine components after the combustor. In this design, a maximum turbine blade temperature limit of $2160^{\circ} \mathrm{R}$ is assumed then used to calculate the chargeable and non-chargeable cooling flow required to meet the limit. ${ }^{15}$ 


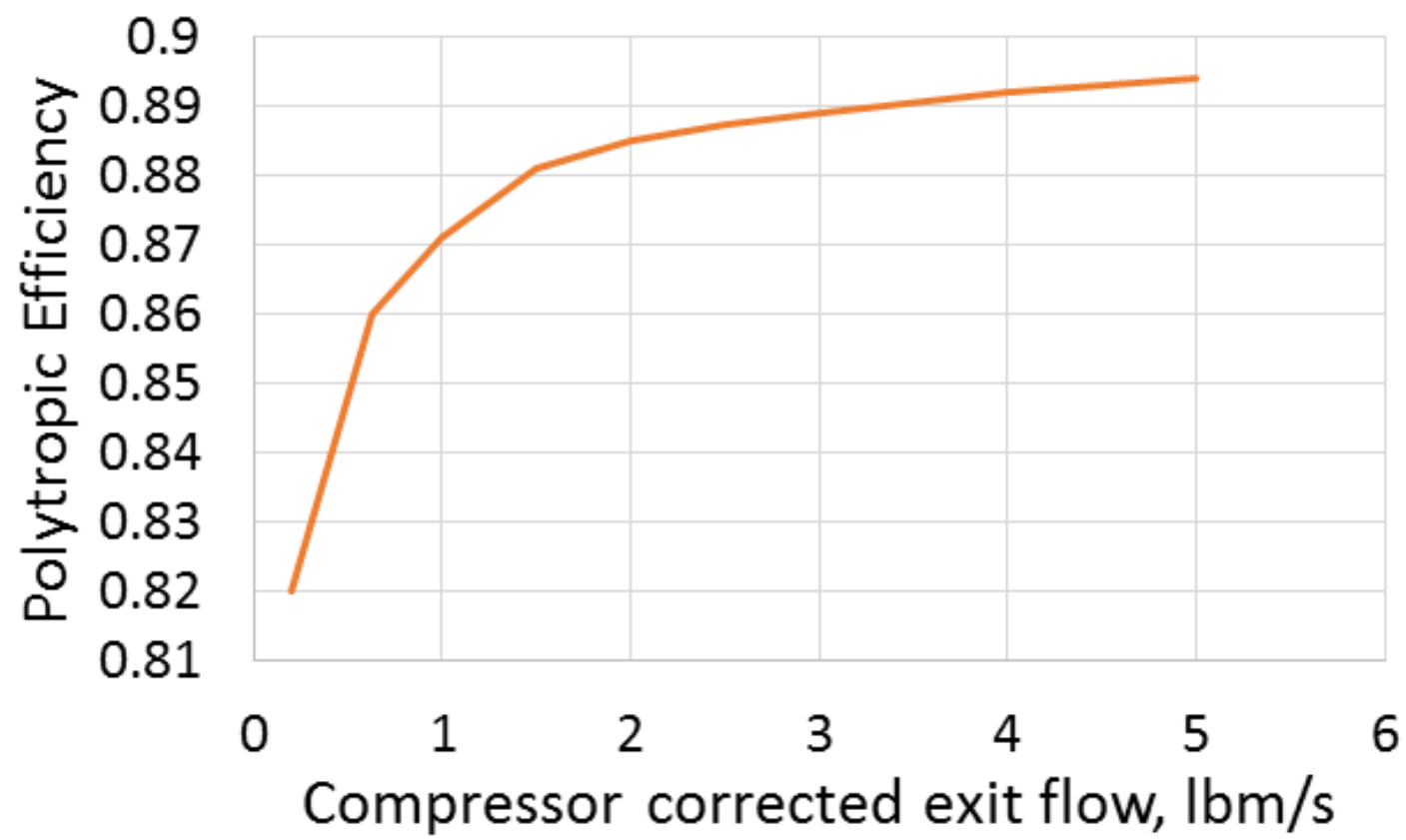

Figure 5. Small engine polytropic efficiency vs. compressor corrected exit flow.

In addition to major internal parameters, an engine dry weight is also calculated. This calculation is based on a correlation between weight and engine core mass flow. Weight and mass flow values for the correlation were gathered from various turboshaft engines with power requirements similar to the concept engine and taken from public sources. ${ }^{16}$ Eight engines from various manufacturers were selected and a linear regression was completed to determine the correlation. The resulting line is shown in Figure 6. Although the model is fairly simple, the correlation is high, with a resulting $\mathrm{R}^{2}$ value of 0.9132 . This indicates a good estimate of engine dry weight that is adequate for a preliminary study.

Table 3. Turboshaft design point definition.

\begin{tabular}{|l|c|c|c|}
\hline \multicolumn{1}{|c|}{ Design Point } & Hover & Cruise & Max Power SLS \\
\hline Altitude, ft & 5000 & 5000 & 0 \\
\hline Mach Number & 0 & $0.3, \sim 200$ knots & 0 \\
\hline $\mathrm{dTs},{ }^{\circ} \mathrm{R}$ & +36 & +36 & 0 \\
\hline Power, hp & 3625 & 1280 & - \\
\hline
\end{tabular}




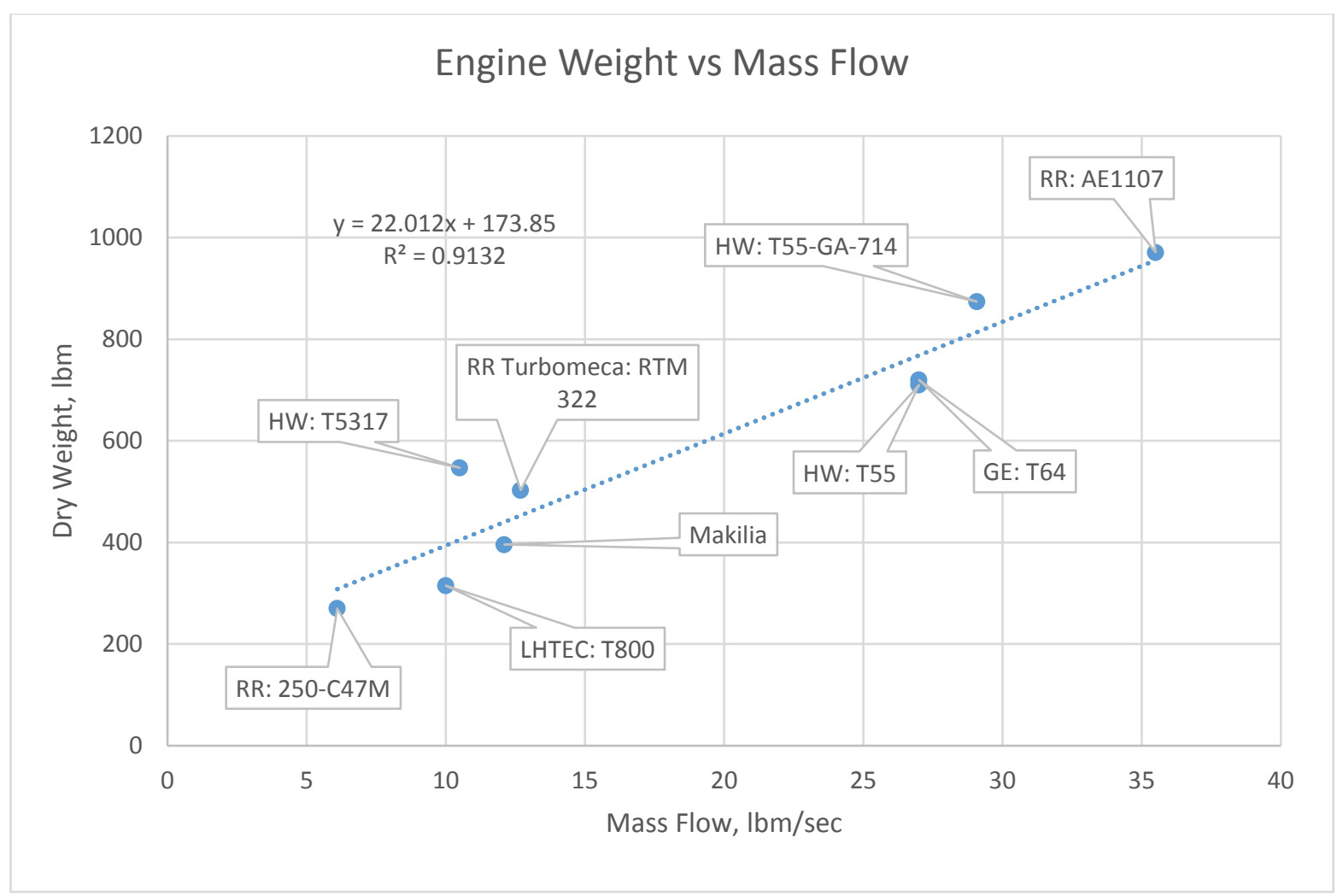

Figure 6. Various small engine dry weight to mass flow values.

\section{Engine Optimization}

The engine optimization model was created to run the three distinct operating points simultaneously. The hover operating point is used as the design point, running to the maximum temperature limit and required thrust level, while also defining engine parameters including: required cooling flow ( $\left.\mathrm{W}_{\text {cool }}\right)$, component efficiencies (Eff), and nozzle throat area (Ath). These engine parameters are fed to the two off-design points, cruise (off design point 1, OD1) and max power (as dictated by the maximum T4 limit) at SLS (off design point 2, OD2). These two points are used to calculate the objectives for optimization: cruise PSFC and SLS weight (considered separately). Note, although weight is calculated at the SLS max power point because data for the correlation model is generated by engines in a test cell running at max power. Another method would be to use a corrected flow for calculation. A diagram of the optimization connections is shown in Figure 7. Elements within the model are defined along the diagonal. Forward feeding connections between elements are shown in the top portion of the diagram, while feedback connections are shown in the bottom half. Model inputs are shown along the top of the diagram. In function, the engine cycle design is run using input pressure ratios $\left(\mathrm{PR}_{\text {comp }}, \mathrm{PR}_{\text {turb }}, \mathrm{PR}_{\mathrm{pt}}\right)$, FAR, element adiabatic efficiencies (Eff $\mathrm{Ediab}_{\text {ab }}$ ), and $\mathrm{W}_{\text {cool }}$ determined from residuals of design parameters and $\mathrm{T} 4, \mathrm{PR}_{\mathrm{noz}}$, blade temperature (Tblade), shaft powers ( $\mathrm{P}_{\text {comp }}, \mathrm{P}_{\text {turb }}, \mathrm{P}_{\mathrm{pt}}$ ), and element polytropic efficiencies $\left(\mathrm{Eff}_{\text {poly }}\right)$. Element map scalars and $\mathrm{W}_{\text {cool }}$ are then fed to each off design case. Off design cases are solved using case parameter determined residuals (Ath, $\mathrm{P}_{\text {comp }}, \mathrm{P}_{\text {turb }}$, and $\mathrm{P}_{\mathrm{pt}}$ or T4) to solve for FAR, $\mathrm{W}$, and $\mathrm{N}_{\text {core }}$ Optimizations of the system is performed by adjusting the system OPR and $\mathrm{T}_{\max }$ with the goal of minimizing engine PSFC or weight. 


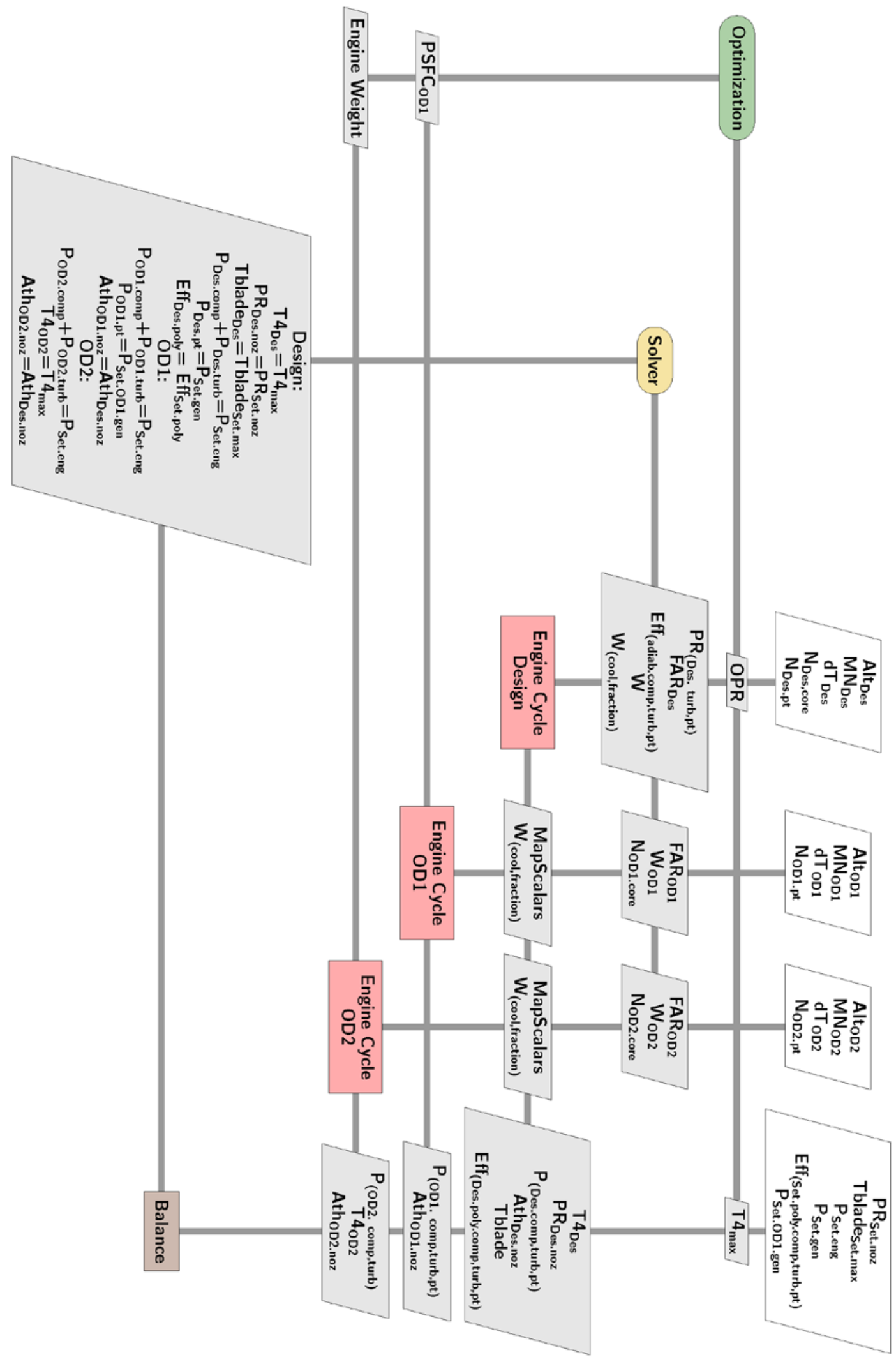

Figure 7. Connection diagram for optimization model. 9

American Institute of Aeronautics and Astronautics 


\section{A. Baseline Optimization and Sensitivity Study}

For this design, overall pressure ratio and the maximum turbine inlet temperature limit at the hover operational point are adjusted as handles to minimize cruise PSFC. A sensitivity study was performed for each of the three operational points to understand the differences in these parameters between the operational points, as shown in Figure 8. In each of the contour plots, it can be seen that PSFC moves lower as OPR is increased. The plots also show that PSFC decreases as maximum T4 increases until the trend reverses around $3300^{\circ} \mathrm{R}$. This reversal is due to the cooling flow. As mentioned in the previous section, the turbine cooling flow is calculated based on the fixed turbine blade temperature limit. This means that as T4 gets hotter, an increasing percentage of the compressor flow needs to be bypassed for cooling. This increasing cooling flow requirement results in the inflection point in PSFC at about $3300^{\circ} \mathrm{R}$. Along with the sensitivity study, separate optimizations were completed to minimize PSFC at hover, cruise, and SLS (Note: design point remains at hover). For each operational point, it can be seen that a maximum OPR of 19 is preferable. Maximum T4 shifts by about $40^{\circ} \mathrm{R}$ between the three points. This would mean, for instance, that if the system was optimized for PSFC at SLS, however the designer's intent was to minimize cruise PSFC, the design would miss the optimization point by about $40^{\circ} \mathrm{R}$, resulting in a small PSFC penalty. For this conceptual engine study, the PSFC shift is negligible and a single design point study would have been acceptable. It should be noted here that the PSFC values for hover and SLS are both lower than those of cruise, which is unfortunate if the cruise point is the most important. This effect is caused because the cruise point is operating at a lower power level than the hover point. With the hover point being the design point, it has the most efficient component operation. This issue can be mitigated by developing the model with the cruise point as the design point with the highest component efficiencies, though core size should still be calculated at the full power SLS point, because the correlation weight model was tuned public data from that point.
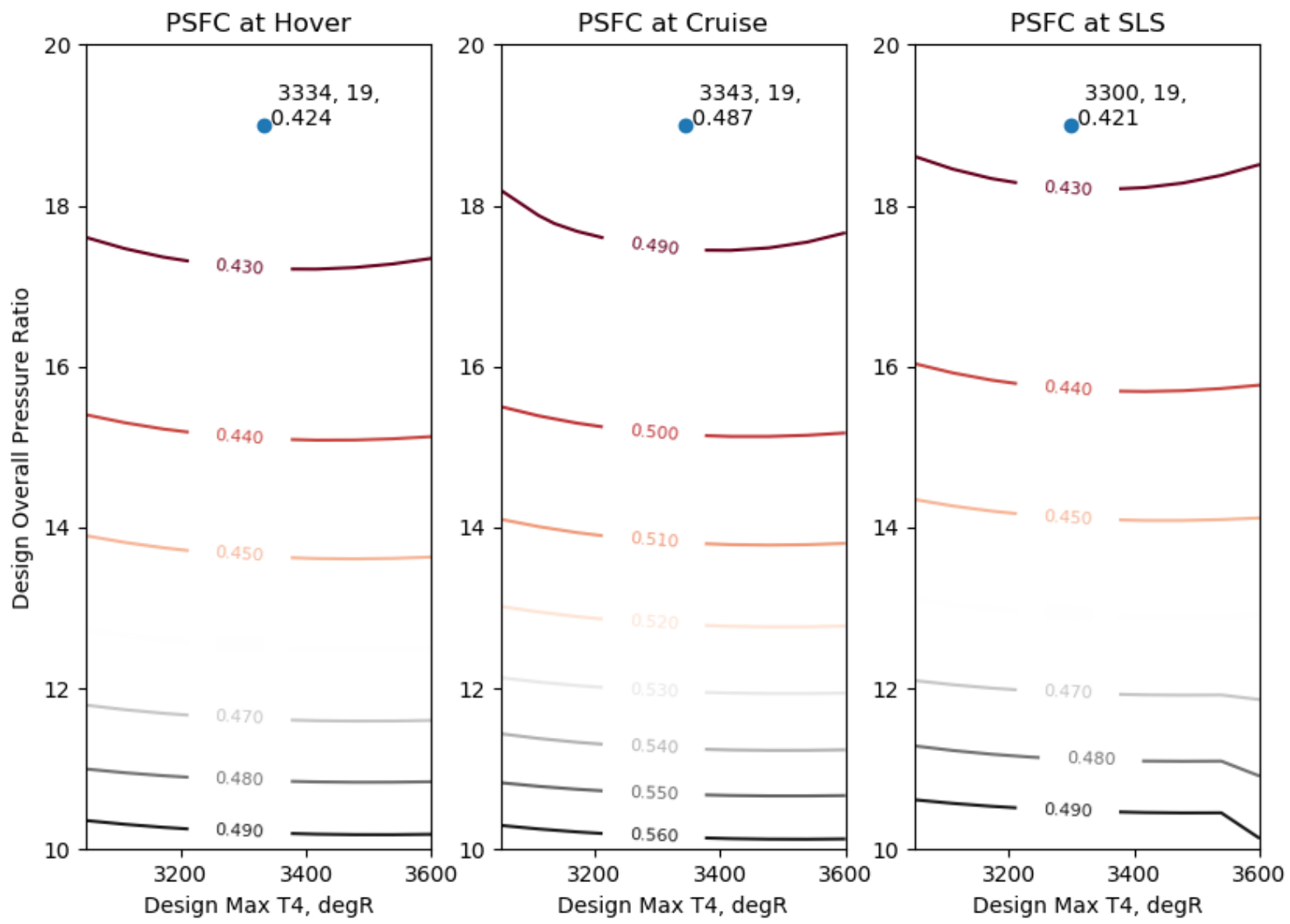

Figure 8. PSFC, lbm/h/shp, for operational points hover, cruise, and SLS optimized with OPR and Maximum T4.

10

American Institute of Aeronautics and Astronautics 
A second study was performed to explore a weight optimized design. The design parameter sensitivity study is shown in Figure 9. In this figure, it may be observed that weight is reduced with increasing T4 limit. This occurs because the higher temperatures are caused by higher fuel to air ratio (FAR). With more fuel and less air, the combustor will burn hotter and the engine will require less overall mass flow to achieve the same power point. Looking at the effects of OPR, it can be seen that initially increases in OPR reduce engine weight while increasing the efficiency of the engine, however as OPR continues to grow the turbine cooling air becomes hotter. This requires additional cooling air and engine weight begins to climb.

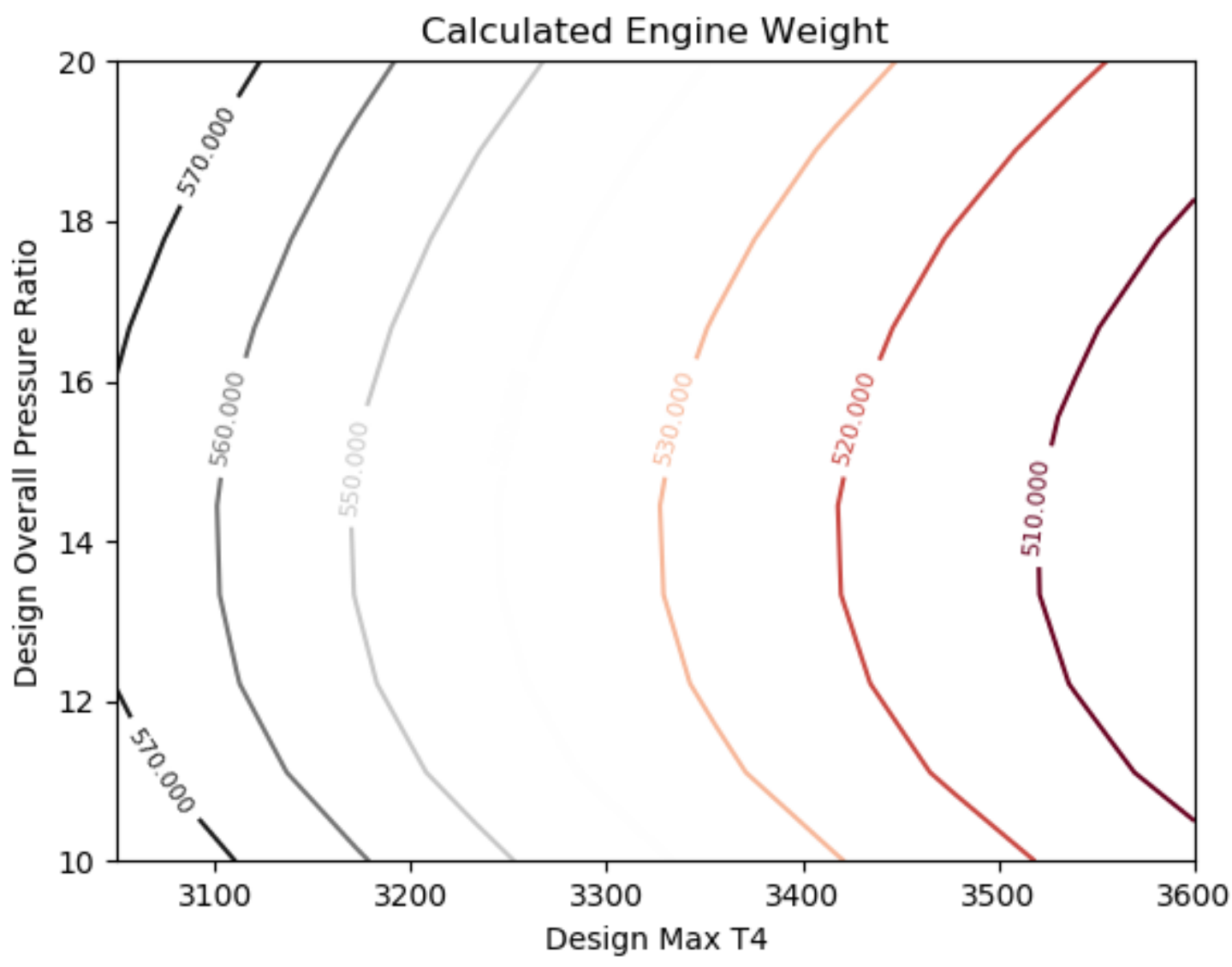

Figure 9. Calculated engine dry weight, lbm.

To analyze the relationship between the two optimizations, a Pareto front is created using the weighted sum method, as shown in Figure 10. In Figure 10, 20 total points were generated with distinct points are marked explicitly. The first point shows the system optimized only for maximum efficiency, resulting in a PSFC of 0.4867 and a weight of $550 \mathrm{lbm}$ at an OPR of 19 and a maximum T4 limit of $3338^{\circ} \mathrm{R}$. The third point demonstrates the system optimized exclusively for weight with a PSFC of 0.5066 and weight of $524 \mathrm{lbm}$ at an OPR of 14.15 and a maximum T4 limit of $3500^{\circ} \mathrm{R}$. The middle point shows the point at which the trade between PSFC and weight is smallest, showing a PSFC of 0.4872 and weight of $533 \mathrm{lbm}$ at an OPR of 19 and maximum T4 limit of $3500^{\circ} \mathrm{R}$. It is interesting to note that this middle point offers the highest T4 limit and OPR that is possible with the design. Designing the engine to this point amounts to a $0.1 \%$ gain in PSFC and a $0.12 \%$ loss in vehicle dry gross weight (as compared with the PSFC optimized point), which are mostly negligible. 


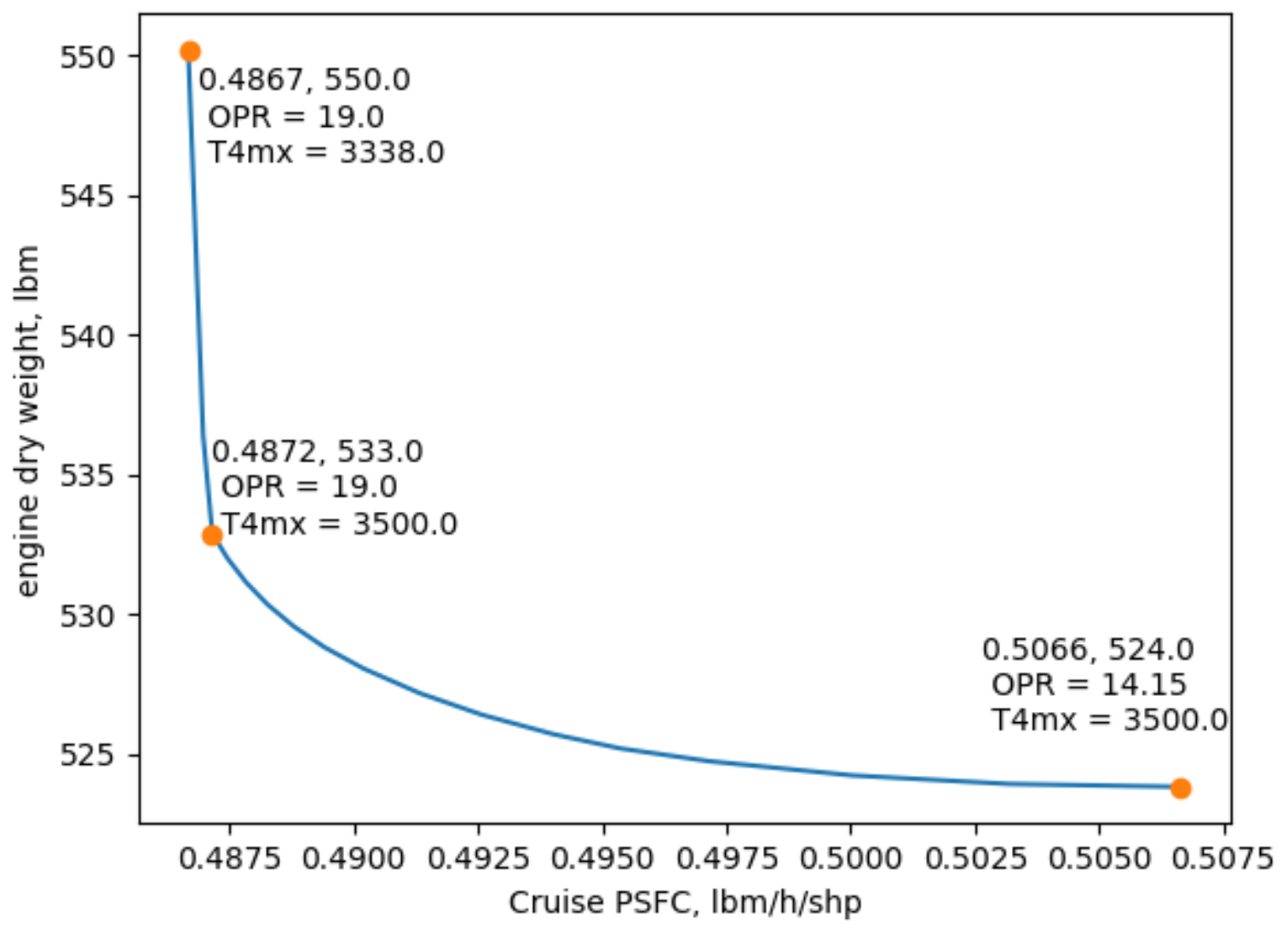

Figure 10. Optimization Pareto front.

\section{B. Design Criteria Sensitivity Study}

Until this point it has been assumed that the requirements for the engine have been fixed. It is important to understand how changes in these underlying requirements affect the system, so that recommendations may be made when changes are proposed. For each of the following optimizations, the system is optimized to minimum PSFC at cruise and the effects on weight are observed.

One consideration when designing this system is the cruise to hover power ratio. Figure 11 shows how adjusting the hover power relative to cruise power affects the PSFC and weight. The baseline power ratio requirement is roughly 3. As the graph shows, when the max power point is reduced, both cruise PSFC and engine weight fall. Convergence of the maximum power point and the cruise point lowers PSFC because it allows the engine to operate closer to the maximum efficiency of the turbomachinery. Also, a reduced maximum power requirement lowers the overall engine size, reducing weight. The optimal maximum T4 limit also shifts higher at larger power ratios as more air is needed at the design point to cool the larger engine. 

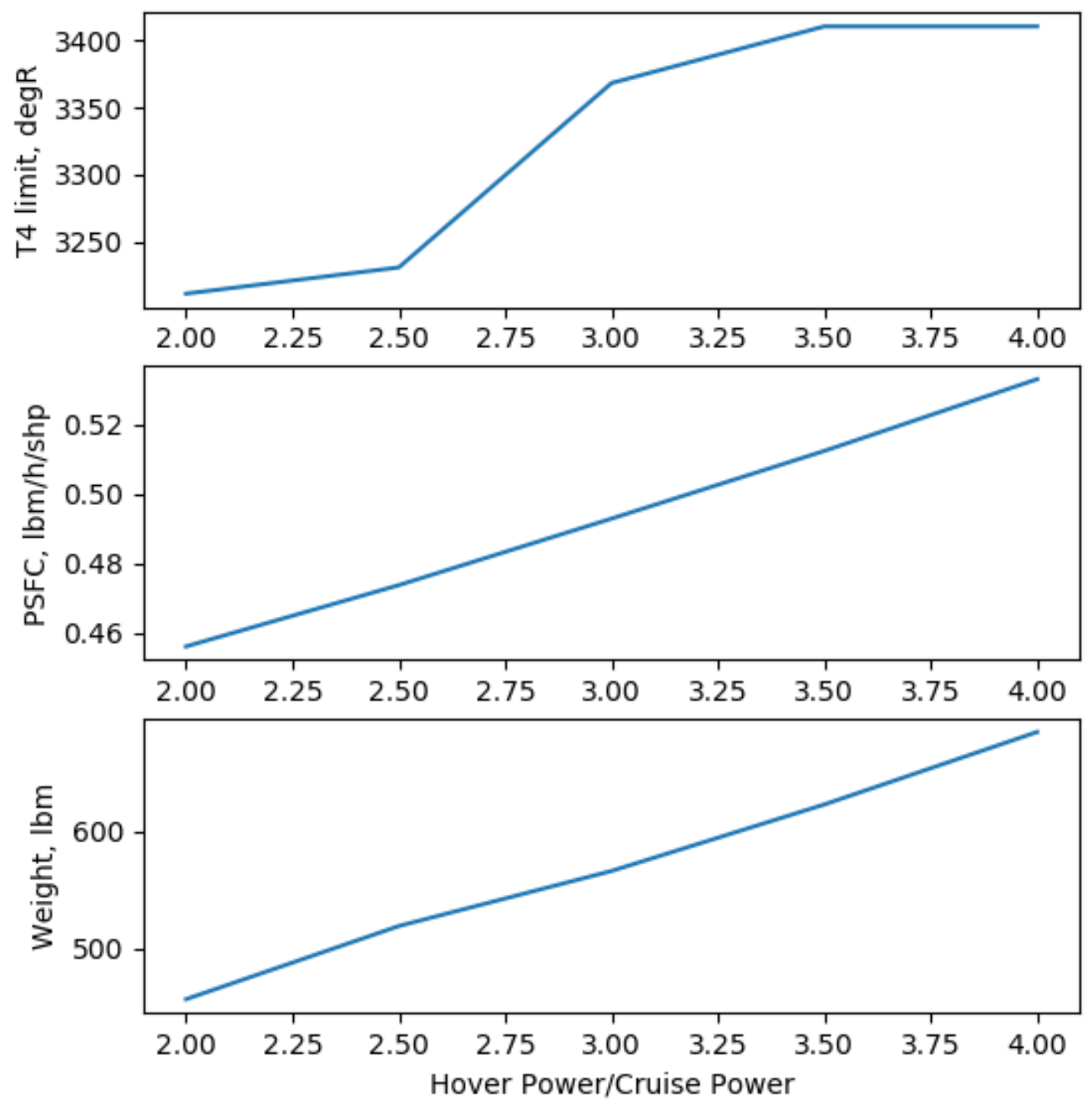

Figure 11. Power ratio vs. T4 limit, weight, and PSFC.

As additional considerations, Figure 12 shows the sensitivity of PSFC and engine weight to adjustments in Alt (for hover and cruise), Mach number (MN, at cruise), and design point nozzle pressure ratio (at hover). Each point on the graph represents a value normalized by the baseline design criteria. For the first of the three graphs (T4 limit), it can be seen that raising the MN reduces the optimum T4 limit as high velocity air increases the temperature of the cooling flow air, reducing its effectiveness at maintaining a high T4 limit. Conversely, increasing altitude or nozzle PR increases the optimal T4 limit. At higher altitude, the small reduction in incoming air temperature decreases the cooling flow temperature and allows for the increase in T4 limit. For nozzle pressure ratio, increases in engine work load associated with higher backend pressure create a need for more fuel, which causes higher T4 temperatures. In the middle graph (PSFC), it can be seen that increasing nozzle pressure ratio raises PSFC as the work load on the engine increases. Increases in Alt and MN both decrease the PSFC. For Alt, decreases in inlet temperature increase the engine efficiency and for MN, inlet pressure increases due to ram air effects. It should be noted that, in this study, drag is not taken into account, and the engine power requirement is not updated for the adjusted speed requirement. While there is a PSFC gain at higher MN, engine power and fuel flow need to be increased to meet higher drag, which would result in a greater amount of fuel burn per distance traveled. Engine weight is examined in the third and final graph. 
In each of the cases a rise in weight may be observed with the increase in design requirement, which can also be related to an increase in engine mass flow. For the increase in nozzle pressure ratio, the additional weight may be attributed to the increase in required power output. Similarly, increasing Alt raises overall engine size because maximum power must be reached at a higher altitude with thinner air. When raising the MN, overall engine size increases because the optimal T4 limit is reduced, causing the acceptable FAR to be reduced. With less acceptable FAR, the engine size must be increased to bring more air and subsequently fuel into the system.
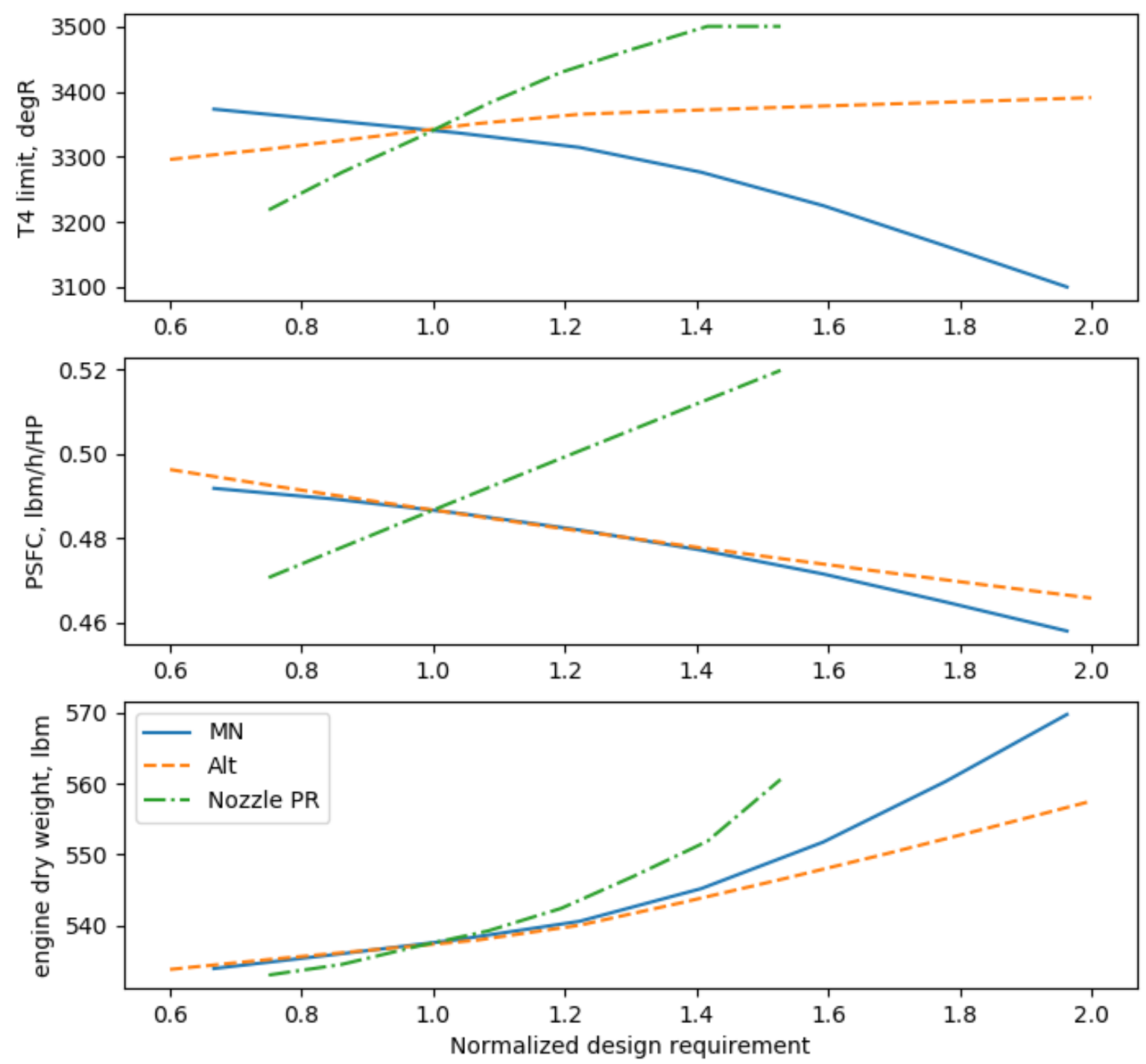

Figure 12. Normalized design requirements vs. T4 limit, weight, and PSFC. 


\section{Conclusions}

This paper details development of a turboshaft engine simulation to be used for a 15 passenger tiltwing turboelectric vehicle. This engine was created to meet an air-taxi mission that constitutes a range of $400 \mathrm{~nm}$ with 8 potential stops that each require a vertical takeoff and landing maneuver. The design was performed around 3 distinct points: hover, cruise, and max power at sea level static conditions, and a multi-point design was performed to guarantee power requirements at each mission design point. The engine model was created using PyCycle and OpenMDAO. An engine system optimization was performed to select overall engine pressure ratio and burner exit temperature (T4) limit by minimizing power specific fuel consumption (PSFC) and engine dry weight. To minimize PSFC, results with the baseline requirements showed that the design favored high overall pressure ratio and a T4 limit that balanced cooling flow capability with the thermodynamic cycle benefit of high temperature operation. To minimize weight, results with the baseline requirements showed that the design favored high T4 limit and an overall pressure ratio that balanced gains in engine efficiency with turbine cooling requirements. In the second part of the study, optimization sensitivity to input design parameters (hover to cruise power ratio, hover and cruise altitude, cruise Mach number, and design nozzle pressure ratio) was examined. Result highlights include: increased cruise PSFC with increasing power ratio, a reduction in optimized T4 limit with increases in cruise Mach number, decreases in cruise PSFC with increases in altitude, and increases in engine weight with increases in any of these criteria. In conclusion, this study offers the first step in a multi-disciplinary optimization where thermal, structural, aerodynamic, trajectory, and acoustics will be combined with this propulsion study to size each component for an optimal system solution. 


\section{Acknowledgments}

The authors would like to thank the NASA Transformational Tools and Technologies (TTT) project, under the Transformative Aeronautics Concept Program (TACP) for the funding of this work. Additionally, the authors would like to thank Christopher Snyder, Eric Hendricks, and Justin Gray of NASA Glenn Research Center for their advice on typical small engine performance and optimization techniques.

\section{References}

${ }^{1}$ Holden, Jeff and Goel, Nikhil, “Fast-Forwarding to a Future of On-Demand Urban Air Transport,” Uber Elevate, white paper, Oct. 27, 2016.

${ }^{2}$ German, B.J., Daskilewicz, M.J., Hamilton, T.K., Warren, M.M., “Cargo Delivery by Passenger eVTOL Aircraft: A Case Study in the San Francisco Bay Area,” 2018 Sciences Meeting, AIAA SciTech Forum, AIAA 2018-2006, Kissimmee, FL, Jan 8-12, 2018. ${ }^{3}$ Duffy, M.J., Wakayama, S., Hupp, R., Lacy, R., Stauffer, M., “A Study in Reducing the Cost of Vertical Flight with Electric Propulsion,” $17^{\text {th }}$ AIAA Aviation Technology, Integration, and Operations Conference, AIAA 2017-3442, Denver, CO, Jun. 5-9, 2017.

4Johnson, W., Silva, C., Solis, E.," Concept Vehicles for VTOL Air Taxi Operations,” AHS Technical Conference on Aeromechanics Design for Transformative Vertical Flight, San Francisco, CA, Jan. 16-19, 2018.

${ }^{5}$ Hendricks, E., Falck, R., Gray, J., Ingraham, D., Chapman, J., Aretskin-Hariton, E., Schnulo, S., Chin, J., Berton, J.,“ Multidisciplinary Optimization of a Turboelectric Tiltwing Urban Air Mobilty Aircraft,” to be presented at the AIAA SciTech Forum, San Diego, CA, Jan 7-11, 2019.

${ }^{6}$ Lyes, R.A., The history of North American small gas turbine aircraft engines, American Institute of Aeronautics and Astronautics, Inc. (AIAA), Reston Virginia, 1999.

${ }^{7}$ Gray, J., Chin, J., Hearn, T., Hendricks, E., Lavelle, T., Martins, J.R.R.A, “Thermodynamics of Gas Turbine Cycles With Analytic Derivatives in OpenMDAO,” AIAA Structures, Structural, Dynamics, and Materials Conference, AIAA SciTech Forum, AIAA 2016-0669, Jan 4-8, San Diego, CA, 2016.

${ }^{8}$ Hearn, T., Hendricks, E., Chin, J., Gray, J., Moore, K.T., "Optimization of Turbine Engine Cycle Analysis with Analytic Derivatives," $17^{\text {th }}$ AIAA/ISSMO Multidisciplinary Analysis and Optimization Conference, AIAA Aviation Forum, AIAA-20164297, June 13-17, Washington D.C., 2016

${ }^{9}$ Gray, J., Moore, K.T., Naylor, B.A., “OpenMDAO: An Open Source Framework for Multidisciplinary Analysis and Optimization.” $13^{\text {th }}$ AIAA/ISSMO Multidisciplinary Analysis and Optimization Conference, AIAA Aviation Forum, AIAA 20109101, Fort Worth, TX, Sept. 13-15, 2010.

${ }^{10}$ Snyder, C.A., “Defining Gas Turbine Engine Performance Requirements for the Large Civil TiltRotor (LCTR2),” NASA/TM2013-2181101, December, 2013.

${ }^{11}$ National Academies of Science, Engineering, and Medicine, Commercial Aircraft Propulsion and Energy Systems

Research: Reducing Global Carbon Emissions, Committee on Propulsion and Energy Systems to Reduce

Commercial Aviation Carbon Emissions Aeronautics and Space Engineering Board Division on Engineering and

Physical Sciences, The National Academies Press, Washington D.C., doi: 10.17226/23490, 2016.

${ }^{12}$ Strack, M., Chiozzotto, G.P., Iwanizki, M., Plohr, M., Kuhn, M., "Conceptual Design Assessment of Advanced Hybrid Electric Turboprop Aircraft Configurations,” 17th AIAA Aviation Technology, Integration, and Operations Conference, AIAA AVIATION Forum, AIAA 2017-3068, Denver, CO, 2017.

${ }^{13}$ Gray, J., Chin, J., Hearn, T., Hendricks, E., Lavelle, T., and J. R. R. A. Martins, "Chemical equilibrium analysis with adjoint derivatives for propulsion cycle analysis,” Journal of propulsion and power, vol. 33, iss. 5, p. 1041-1052, 2017.

${ }^{14}$ Snyder, C.A., "Exploring advanced technology gas turbine engine design and performance for the Large Civil Tiltrotor (LCTR)," 50th AIAA/ASME/SAE/ASEE Joint Propulsion Conference, AIAA Propulsion and Energy Forum, AIAA 2014-3442, July 9-11, 2014.

${ }^{15}$ Gauntner, J. W., “Algorithm for Calculating Turbine Cooling Flow and the Resulting Decrease in Turbine Efficiency,” NASA TM 81453, 1980.

${ }^{16}$ Daly, M., Gunston, B., Janes’s Aero Engines, Issue Twenty-nine, Jane’s Information Group, Alexandria, Virginia, March, 2011. 